\title{
Dynamic Property Investigation of Sandwich Acoustic Black Hole Beam with Clamped-Free Boundary Condition
}

\author{
Xiaofei Du $\left(\mathbb{D}\right.$, Dacheng Huang $\mathbb{D}$, and Jianrun Zhang $\mathbb{D}^{\mathbb{D}}$ \\ School of Mechanical Engineering, Southeast University, Nanjing, China \\ Correspondence should be addressed to Jianrun Zhang; zhangjr@seu.edu.cn
}

Received 29 April 2019; Revised 15 July 2019; Accepted 25 July 2019; Published 6 August 2019

Academic Editor: Giuseppe Petrone

Copyright (C) 2019 Xiaofei Du et al. This is an open access article distributed under the Creative Commons Attribution License, which permits unrestricted use, distribution, and reproduction in any medium, provided the original work is properly cited.

\begin{abstract}
The geometric parameters of the acoustic black hole $(\mathrm{ABH})$ structure are changed in power exponent, and this feature can be used to control the flexural wave to achieve energy concentration, vibration attenuation, or noise reduction. However, in practice, the $\mathrm{ABH}$ structure often has a truncation due to the limitation of manufacturing, which will cause the reflection coefficient to increase significantly and seriously affect the $\mathrm{ABH}$ effect. In this paper, a semianalytical model of the sandwich-truncated $\mathrm{ABH}$ beam structure with aluminum in the middle layer and steel in the upper and lower layers is constructed based on the energy principle. The ABH effect of the sandwich beam under the clamped-free boundary condition is analyzed. Meanwhile, the effects of damping layer parameters, middle layer material, and thickness on the vibrational acceleration response of the $\mathrm{ABH}$ region and the uniform beam region of the sandwich beam are also studied. It is observed that, for the sandwich $\mathrm{ABH}$ beam structure, the influence of damping layer thickness on the acceleration response peak values of both the $\mathrm{ABH}$ region and the uniform region is very obvious in middle and high frequencies and the peaks at about $9 \mathrm{kHz}$ are completely suppressed when the damping layer thickness reaches $3 \mathrm{~mm}$. It also reveals that the use of aluminum as the middle layer material can bring a vibration attenuation at around $9 \mathrm{kHz}$ both for the $\mathrm{ABH}$ region and the uniform beam region compared with using steel as the middle layer material. Experiments are carried out to verify the accuracy of simulation analysis.
\end{abstract}

\section{Introduction}

In the past two decades, the acoustic black hole $(\mathrm{ABH})$ structure has attracted a lot of attention as a new method of vibration attenuation and noise reduction, and it can also bring positive effects to structural lightweighting [1-3]. Similar to the concept of the astronomical black hole, an acoustic black hole can reduce the velocity of sound wave propagation. Ideally, the sound wave velocity drops to zero to achieve zero reflection. Mironov found that, in the thinplate wedge structure, if the thickness of the structure is reduced by a certain power function (the power exponent is not less than 2), the wave velocity of the flexural wave will decrease rapidly with the decrease of the thickness [4]. In an ideal case, the wave velocity can be reduced to zero to achieve zero reflection of the flexural wave and this structure is called the $\mathrm{ABH}$ structure [4]. By utilizing the above characteristics of the $\mathrm{ABH}$ structure, it is possible to design an $\mathrm{ABH}$ region in beam or plate structures to achieve vibration attenuation [5], sound radiation reduction [6, 7], and energy harvesting $[8,9]$.

In the actual manufacturing, a truncation at the tip end of the $\mathrm{ABH}$ region is inevitable. Even a small thickness of truncation can significantly increase the reflection coefficient, seriously affecting the effectiveness of energy concentration and vibration attenuation [10]. In order to improve the energy concentration effect of the truncated $\mathrm{ABH}$ structure, some measures have been taken, such as the sticking damping material on the edge of the $\mathrm{ABH}$ area, which can significantly reduce the reflection coefficient $[11,12]$.

To analyze the performance of the $\mathrm{ABH}$ structure and the effect of damping layers or other attachments on the dynamic property of the entire system, we need to resort to some analytical or numerical approach. The analysis methods for $\mathrm{ABH}$ beam structures are geometrical acoustic 
method, impedance method, semianalytical method, and finite element method (FEM). The geometrical acoustic method is based on the assumption that the thickness of the damping layer is much smaller than the thickness of the $\mathrm{ABH}$ structure. For $\mathrm{ABH}$ structures with a certain thickness of the damping layer, the calculation accuracy is greatly affected and the influence of variation of the thickness and length of the damping layer on the dynamic characteristics of the $\mathrm{ABH}$ structure could not be studied [13]. The structural impedance method considers a semi-infinite structure in modeling analysis, while the $\mathrm{ABH}$ structures existing in reality are often limited and have different boundary conditions [14]. Recently, Tang et al. established a semianalytical model of one-dimensional ABH structure based on the Lagrangian variational principle. The damping layers or other structures are attached to the whole system through energy terms, and the dynamic response of the $\mathrm{ABH}$ beam is studied by using rotational spring and translational spring to simulate different boundary conditions [15]. On the basis of the semianalytical method, Deng et al. used the Gaussian function to fit the displacement field of the ABH structure and established a semianalytical model with a passively constrained viscoelastic layer (PCVL) [16]. Wang et al. established a semianalytical model for power flow and structural intensity analysis of an $\mathrm{ABH}$ beam by using an improved Fourier series with auxiliary terms to construct the admissible function [17]. Besides the semianalytical method analysis, Ji et al. proposed an analytical expression of the wave reflection coefficient in a modified one-dimensional $\mathrm{ABH}$ and carried out a time-domain experiment based on a laser excitation technique to visualize the wave propagation [18]. On the contrary, the laminated beams or plates are an important type of structures in engineering with the advantages of lightweighting and high strength-mass ratio than the singlelayered structure, and many researchers have carried out lots of studies on composite beams [19]. In the present work, we will adopt the semianalytical method to analyze a sandwich $\mathrm{ABH}$ beam. Different from the existing models, the object studied in this paper is a laminated sandwich $\mathrm{ABH}$ beam structure with an aluminum layer in the middle and steel in the upper and lower layers,so the segmentation and material variations for different layers are needed to be taken into consideration in the modeling procedure.

In this paper, a sandwich $\mathrm{ABH}$ beam structure with truncation at the tip of the $A B H$ region is proposed. Unlike previous one-dimensional $\mathrm{ABH}$ structures, the $\mathrm{ABH}$ beam investigated in this paper is a sandwich beam composed of three layers. The middle layer material of the proposed $A B H$ beam is aluminum, and the upper and lower layers are steel. The sandwich $\mathrm{ABH}$ beam is an elongated load-bearing structure composed of three layers of materials bonded together, and its length is much larger than the width and thickness. The Euler-Bernoulli beam theory can analyze the dynamics of slender laminated beams accurately [19]. A semianalytical model of the $\mathrm{ABH}$ sandwich beam with truncation is established in this paper based on the Euler-Bernoulli laminated beam theory. The dynamic property of the $\mathrm{ABH}$ region and the uniform region of the sandwich $\mathrm{ABH}$ beam structure is analyzed. Then, the effects of parameters of the damping layer and variations of the middle layer on the dynamic response of the proposed sandwich ABH beam are studied. Experimental measurement was also conducted to verify the accuracy of the numerical simulation.

\section{Dynamic Model of a Sandwich ABH Beam}

2.1. Modeling of a Sandwich ABH Beam. As shown in Figure 1 , let us consider a center-symmetric sandwich beam with a truncated acoustic black hole region at the right end of the beam. Damping layers are attached to the $\mathrm{ABH}$ region, its thickness is $h_{\mathrm{d}}(x)$, and its width is equal to the width of the bare beam. The width and height of the bare beam are much smaller than its length. The length of the sandwich $\mathrm{ABH}$ beam ranges from $x_{0}$ to $x_{\mathrm{b} 3}$, among which the length of the $\mathrm{ABH}$ region varies from $x_{0}$ to $x_{\mathrm{b} 2}$. The thickness of the uniform region of the sandwich beam is $h_{\mathrm{b} 1}, h_{\mathrm{b} 2}$, and $h_{\mathrm{b} 3}$. Since the beam in Figure 1 is a three-layered structure, the length of the $\mathrm{ABH}$ region is divided into two parts: $\left(x_{0}, x_{\mathrm{b} 1}\right)$ and $\left(x_{\mathrm{b} 1}, x_{\mathrm{b} 2}\right)$. The thickness of the truncation is $h_{\mathrm{t}}$, and the position of the point force excitation is $x_{\mathrm{f}}$.

The thickness of the bare $\mathrm{ABH}$ beam is given by

$$
h_{\mathrm{b}}= \begin{cases}\varepsilon\left(x-x_{0}\right)^{2}+\frac{h_{\mathrm{t}}}{2}, & x_{0} \leq x \leq x_{\mathrm{b} 2}, \\ h_{\mathrm{b} 1}+h_{\mathrm{b} 2}+h_{\mathrm{b} 3}, & x_{\mathrm{b}_{2}} \leq x \leq x_{\mathrm{b} 3} .\end{cases}
$$

The entire system is symmetric about the $x$-axis. The $\mathrm{ABH}$ region of the sandwich beam is free, and the other end is supported by a rotating spring and a translational spring to achieve different boundary conditions. For example, when the stiffnesses of the rotating spring and the translational spring are set extremely high, the boundary condition of the sandwich $\mathrm{ABH}$ beam is clamped free. While fixing both the stiffnesses of the rotating spring and the translational spring zero, the boundary condition of the sandwich $\mathrm{ABH}$ beam is clamped-free. Besides, other boundary conditions can be obtained by changing the value of $q$ and $k$.

In order to analyze the dynamic properties of the sandwich $\mathrm{ABH}$ beam, the following assumptions are made:

(1) Shear deformation of the cross section perpendicular to the neutral axis is ignored

(2) The movement of the beam only occurs in the $x-z$ plane with small deflection

(3) Only the normal stress of the damping layer is considered, regardless of the shear stress of the damping layer

(4) Ignore the moment of inertia effect of the sandwich $\mathrm{ABH}$ beam

According to the Euler-Bernoulli beam theory, the displacement field of the $\mathrm{ABH}$ beam can be written as follows:

$$
\{u, w\}=\left\{-z \frac{\partial w}{\partial x}, w(x, t)\right\}
$$




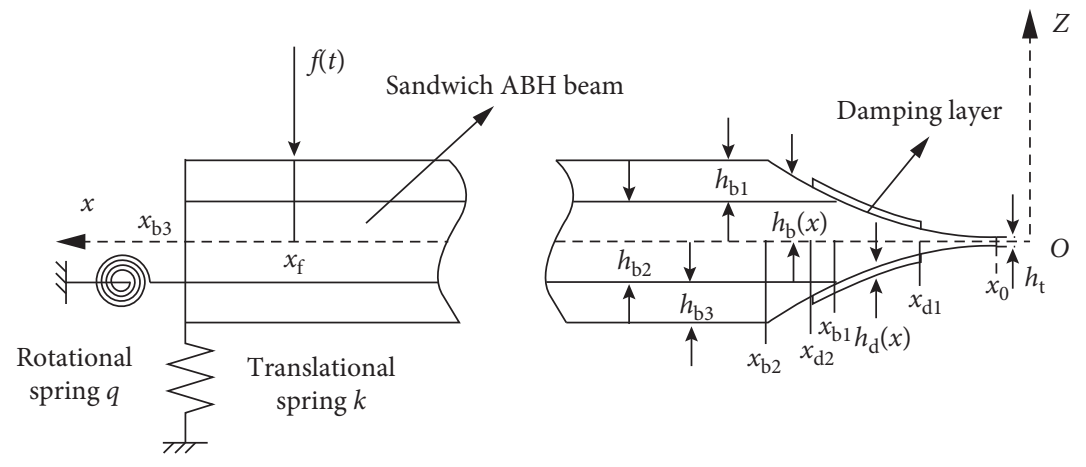

Figure 1: An Euler-Bernoulli sandwich beam with truncated ABH.

where the vector $\{u, w\}$ represents the displacement of any point on the sandwich $\mathrm{ABH}$ beam, $w(x, t)$ represents the deflection curve of the beam at different times, and $\partial w / \partial x$ represents the deflection angle of the beam at position $x$. Based on the separation variable method, the deflection curve of the sandwich beam can be expressed as

$$
w(x, t)=\sum_{i} P_{i}(t) \varphi_{i}(x)=\mathbf{P}^{\mathrm{T}} \boldsymbol{\varphi}=\varphi^{\mathrm{T}} \mathbf{P},
$$

where $\varphi_{i}(x)$ is the admissible shape function solely depending on coordinate $x$ and $P_{i}(t)$ is time dependent and corresponding to weight coefficients to be assigned to the shape function.

The kinetic energy of the system can be obtained by

$$
T=T_{\mathrm{b} 1}+T_{\mathrm{b} 2}+T_{\mathrm{b} 3}+T_{\text {damp }},
$$

where $T_{\mathrm{b} 1}, T_{\mathrm{b} 2}$, and $T_{\mathrm{b} 3}$ are the kinetic energies of the three layers of the sandwich $\mathrm{ABH}$ beam and $T_{\text {damp }}$ is the kinetic energy of the damping layer attached on the beam. They can be computed as

$$
\begin{aligned}
T_{\mathrm{b} 1} & =\frac{1}{2} \int_{x_{\mathrm{b} 1}}^{x_{\mathrm{b} 3}} \rho_{\mathrm{b} 1} A_{\mathrm{b} 1}\left(\frac{\partial w}{\partial t}\right)^{2} d x, \\
T_{\mathrm{b} 2} & =\frac{1}{2} \int_{x_{0}}^{x_{\mathrm{b} 3}} \rho_{\mathrm{b} 2} A_{\mathrm{b} 2}\left(\frac{\partial w}{\partial t}\right)^{2} d x, \\
T_{\mathrm{b} 3} & =\frac{1}{2} \int_{x_{\mathrm{b} 1}}^{x_{\mathrm{b} 3}} \rho_{\mathrm{b} 3} A_{\mathrm{b} 3}\left(\frac{\partial w}{\partial t}\right)^{2} d x, \\
T_{\mathrm{damp}} & =\int_{x_{\mathrm{d} 1}}^{x_{\mathrm{d} 2}} \rho_{\mathrm{damp}} A_{\mathrm{damp}}\left(\frac{\partial w}{\partial t}\right)^{2} d x,
\end{aligned}
$$

where $\rho_{\mathrm{b} 1}, \rho_{\mathrm{b} 2}, \rho_{\mathrm{b} 3}$, and $\rho_{\mathrm{damp}}$ are the densities of the three layer materials and the damping layer material. $A_{\mathrm{b} 1}, A_{\mathrm{b} 2}$, $A_{\mathrm{b} 3}$, and $A_{\text {damp }}$ are the cross-sectional areas of each layer of the sandwich $\mathrm{ABH}$ beam and the damping layer. The potential energy of the system can be found as

$$
V=V_{\mathrm{b} 1}+V_{\mathrm{b} 2}+V_{\mathrm{b} 3}+V_{\text {damp }}+V_{\text {edge }},
$$

where $V_{\mathrm{b} 1}, V_{\mathrm{b} 2}$, and $V_{\mathrm{b} 3}$ represent the potential energies of the three layers, $V_{\text {damp }}$ represents the potential energy of the damping layer, and $V_{\text {edge }}$ represents the potential energy of the rotating spring and the translational spring. They are expressed as

$$
\begin{aligned}
V_{\mathrm{b} 1} & =\frac{1}{2} \int_{x_{\mathrm{b} 1}}^{x_{\mathrm{b} 2}} E_{\mathrm{b} 1} I_{\mathrm{b} 1}\left(\frac{\partial^{2} w}{\partial x^{2}}\right) d x, \\
V_{\mathrm{b} 2} & =\frac{1}{2} \int_{x_{\mathrm{b} 0}}^{x_{\mathrm{b} 3}} E_{\mathrm{b} 2} I_{\mathrm{b} 2}\left(\frac{\partial^{2} w}{\partial x^{2}}\right) d x, \\
V_{\mathrm{b} 3} & =\frac{1}{2} \int_{x_{\mathrm{b} 1}}^{x_{\mathrm{b} 2}} E_{\mathrm{b} 3} I_{\mathrm{b} 3}\left(\frac{\partial^{2} w}{\partial x^{2}}\right) d x, \\
V_{\mathrm{damp}} & =\frac{1}{2} \int_{x_{\mathrm{d} 1}}^{x_{\mathrm{d} 2}} E_{\mathrm{damp}} I_{\mathrm{damp}}\left(\frac{\partial^{2} w}{\partial x^{2}}\right) d x, \\
V_{\text {edge }} & =\frac{1}{2} k w\left(x_{\mathrm{b} 3}, t\right)^{2}+\frac{1}{2} q\left(\frac{\partial w\left(x_{\mathrm{b} 3}, t\right)}{\partial x}\right)^{2},
\end{aligned}
$$

where $E_{\mathrm{b} 1}, E_{\mathrm{b} 2}$, and $E_{\mathrm{b} 3}$ stand for Young's modulus of the three layers and $E_{\text {damp }}$ stands for Young's modulus of the damping layer. $I_{\mathrm{b} 1}, I_{\mathrm{b} 2}$, and $I_{\mathrm{b} 3}$ are the inertias of the three layers of the sandwich $\mathrm{ABH}$ beam at coordinate $x . I_{\mathrm{damp}}$ is the inertia of the damping layer at coordinate $x$. The damping layer is embedded as a part of the energy expression of the entire system, and it is fully coupled to the bare $\mathrm{ABH}$ beam. Considering the structural damping of the system, Young's modulus in equations (7)-(10) will be multiplied by $\left(1+\eta_{n}\right)$, and $\eta_{n}(n=1,2,3, \ldots)$ represents the damping loss factors of the three layers and the damping layer of the sandwich $\mathrm{ABH}$ beam.

The work done by the external force $f(t)$ acting on the $\mathrm{ABH}$ beam at $x_{\mathrm{f}}$ is given by

$$
W=f(t) \cdot w\left(x_{\mathrm{f}}, t\right) .
$$

The Lagrangian of the entire system can be expressed as

$$
L=T+V-W .
$$

According to the Hamiltonian equation, the following Lagrangian equation can be obtained after a series of transformation:

$$
\left(\mathbf{K}-\omega^{2} \mathbf{M}\right) \mathbf{A}=\mathbf{F},
$$


where $\mathbf{M}$ and $\mathbf{K}$ stand for the mass matrix and stiffness matrix of the whole system. Due to the consideration of the damping loss factors of the three layers and the damping layer, the stiffness matrix is complex. The response of the entire system under forced vibration can be obtained by solving equation (14). When $\mathbf{F}$ is set to zero, the natural frequencies and mode shapes of the sandwich $\mathrm{ABH}$ beam can be obtained.

The mass matrix of the entire system can be written as

$$
\begin{aligned}
\mathbf{M}= & 2 \mathbf{M}^{\text {steel }}+\mathbf{M}^{\mathrm{AL}}+\mathbf{M}^{\mathrm{damp}}=2 \mathbf{M}^{\text {steel_Uni }}+\mathbf{M}^{\mathrm{AL} \_ \text {Uni }} \\
& +2 \mathbf{M}^{\text {steel_ABH }}+\mathbf{M}^{\mathrm{AL} \_\mathrm{ABH}}+\mathbf{M}^{\text {damp }} .
\end{aligned}
$$

For each part of the sandwich $\mathrm{ABH}$ beam, the mass matrices are expressed as

$$
\begin{aligned}
\mathbf{M}^{\mathrm{damp}} & =2 \rho_{\mathrm{d}} \int_{x_{\mathrm{d} 1}}^{x_{\mathrm{d} 2}} \boldsymbol{\varphi} \varphi^{T} h_{\mathrm{d}}(x) d x, \\
\mathbf{M}^{\mathrm{Uni}} & =2 \rho h \int_{x_{2}}^{x_{3}} \boldsymbol{\varphi} \boldsymbol{\varphi}^{T} d x, \\
\mathbf{M}^{\mathrm{ABH}} & =2 \varepsilon \rho \int_{x_{1}}^{x_{2}} \boldsymbol{\varphi} \varphi^{T} h_{\mathrm{b}}(x) x^{2} d x .
\end{aligned}
$$

In (17) and (18), the upper and lower limits of the integral of the mass matrix are the starting and ending coordinates of the length of each layer along the $x$-axis. For example, when the equations are used to calculate the mass matrix of the steel layer, the upper and lower limits of the integral are $\left(x_{\mathrm{b} 1}, x_{\mathrm{b} 2}\right)$ and $\left(x_{\mathrm{b} 2}, x_{\mathrm{b} 3}\right)$. When we use the equations to calculate the mass matrix of the aluminum layer, the upper and lower limits of the integral are $\left(x_{0}, x_{\mathrm{b} 1}\right)$ and $\left(x_{\mathrm{b} 1}, x_{\mathrm{b} 3}\right)$.

The stiffness matrix of the entire system is given by

$$
\begin{aligned}
\mathbf{K}= & 2 \mathbf{K}^{\text {steel }}+\mathbf{K}^{\mathrm{AL}}+\mathbf{K}^{\text {damp }}+\mathbf{K}^{\text {edge }} \\
= & 2 \mathbf{K}^{\text {steel_Uni }}+\mathbf{K}^{\mathrm{AL} \_ \text {Uni }}+2 \mathbf{K}^{\text {steel_ABH }}+\mathbf{K}^{\mathrm{AL} \_\mathrm{ABH}} \\
& +\mathbf{K}^{\text {damp }}+\mathbf{K}^{\text {edge }} .
\end{aligned}
$$

For each part of the sandwich $\mathrm{ABH}$ beam, the stiffness matrices are computed by

$$
\begin{aligned}
\mathbf{K}^{\mathrm{Uni}}= & \frac{2}{3} E h^{3} \int_{x_{2}}^{x_{3}} \frac{\partial^{2} \boldsymbol{\varphi}}{\partial x^{2}} \frac{\partial^{2} \boldsymbol{\varphi}^{T}}{\partial x^{2}} d x, \\
\mathbf{K}^{\mathrm{ABH}}= & \frac{2}{3} E \varepsilon^{3} \int_{x_{1}}^{x_{2}} \frac{\partial^{2} \boldsymbol{\varphi}}{\partial x^{2}} \frac{\partial^{2} \boldsymbol{\varphi}^{T}}{\partial x^{2}} x^{6} d x, \\
\mathbf{K}^{\mathrm{damp}}= & \frac{2}{3} E_{\mathrm{d}} \int_{x_{\mathrm{d} 1}}^{x_{\mathrm{d} 2}} \frac{\partial^{2} \boldsymbol{\varphi}}{\partial x^{2}} \frac{\partial^{2} \boldsymbol{\varphi}^{T}}{\partial x^{2}}\left(3 \varepsilon^{2} x^{4} h_{\mathrm{d}}(x)\right. \\
& \left.+3 \varepsilon x^{2} h_{\mathrm{d}}(x)^{2}+h_{\mathrm{d}}(x)^{3}\right) d x, \\
\mathbf{K}^{\text {edge }}= & k \boldsymbol{\varphi}\left(x_{\mathrm{b} 3}\right) \boldsymbol{\varphi}^{T}\left(x_{\mathrm{b} 3}\right) \\
& +q \frac{\partial \boldsymbol{\varphi}}{\partial x}\left|x=x_{\mathrm{b} 3} \frac{\partial \varphi^{T}}{\partial x}\right| x=x_{\mathrm{b} 3} .
\end{aligned}
$$

Similar to the expression of the mass matrix, the upper and lower limits of the integral in equations (20) and (21) are $\left(x_{\mathrm{b} 1}, x_{\mathrm{b} 2}\right)$ and $\left(x_{\mathrm{b} 2}, x_{\mathrm{b} 3}\right)$ for the steel layer and $\left(x_{0}, x_{\mathrm{b} 1}\right)$ and $\left(x_{\mathrm{b} 1}, x_{\mathrm{b} 3}\right)$ for the aluminum layer.

Since the stiffness matrix $\mathbf{K}$ is complex, the eigenvalues of the proposed beam are given by

$$
\omega^{2}=\omega_{n}^{2}(1+i \eta),
$$

where $\omega_{n}$ is the natural frequency and $\eta$ is the loss factor of the sandwich $\mathrm{ABH}$ beam.

2.2. Shape Function Fitting the Displacement Field. To fit the displacement filed of nonuniform beams or plates, the polynomial functions have been used to solve linear or nonlinear thickness variation of the nonuniform beams $[20,21]$ or plates $[22,23]$. However, due to the thickness of the sandwich $\mathrm{ABH}$ beam dwindling to zero rapidly in the $\mathrm{ABH}$ region, the above functions are not able to accurately present the displacement of the sandwich $\mathrm{ABH}$ beam. The Mexican hat wavelets (MHWs) have been demonstrated suitable to analyze the displacement field of the ABH beam in [15]. The MHW function has the standard form after normalization [24]:

$$
\varphi(x)=\frac{2}{\sqrt{3}} \pi^{-1 / 4}\left(1-x^{2}\right) \exp \left(-\frac{x^{2}}{2}\right) .
$$

The MHW function is the second derivative of the Gaussian distribution function. It can be seen that, from equation (25), the MHW function is symmetric about the $y$ axis, with an amplitude of $2 / \sqrt{3} \pi^{-1 / 4}$. The MHW function can be expanded as the following a set of functions after the wavelet transform:

$$
\varphi_{j, k}(x)=\frac{2}{\sqrt{3}} \pi^{-1 / 4} 2^{j / 2}\left[1-\left(2^{j} x-k\right)^{2}\right] \exp \left[-\frac{\left(2^{j} x-k\right)^{2}}{2}\right],
$$

where the integer $j$ is the scaling parameter determining the calculation accuracy of the present model and the integer $k$ is the translation parameter which determines the dimensions of the mass matrix and the stiffness matrix. The values of the MHW under different scaling parameters $j$ and translation parameters $k$ are shown in Figure 2. It shows that, by changing the values of $j$ and $k$, the MHW can be scaled and translated to fit the displacement field of different $\mathrm{ABH}$ beams.

The key to fitting the shape function of the semianalytical model using MHW is to determine the value ranges of $j$ and $k$. Meanwhile, the mass matrix $\mathbf{M}$ and the stiffness matrix $\mathbf{K}$ should be eliminated when singularity occurs during calculation. When the length domain of the sandwich $\mathrm{ABH}$ beam is $\left(x_{0}, x_{\mathrm{b} 3}\right)$, the value of $k$ should be

$$
\begin{array}{r}
k=\left[-4+m-j+l\left(x_{0} 2^{j}\right), u\left(x_{\mathrm{b} 3} 2^{j}\right)+4-m+j\right], \\
j=0,1,2, \ldots, m, m \leq 5,
\end{array}
$$




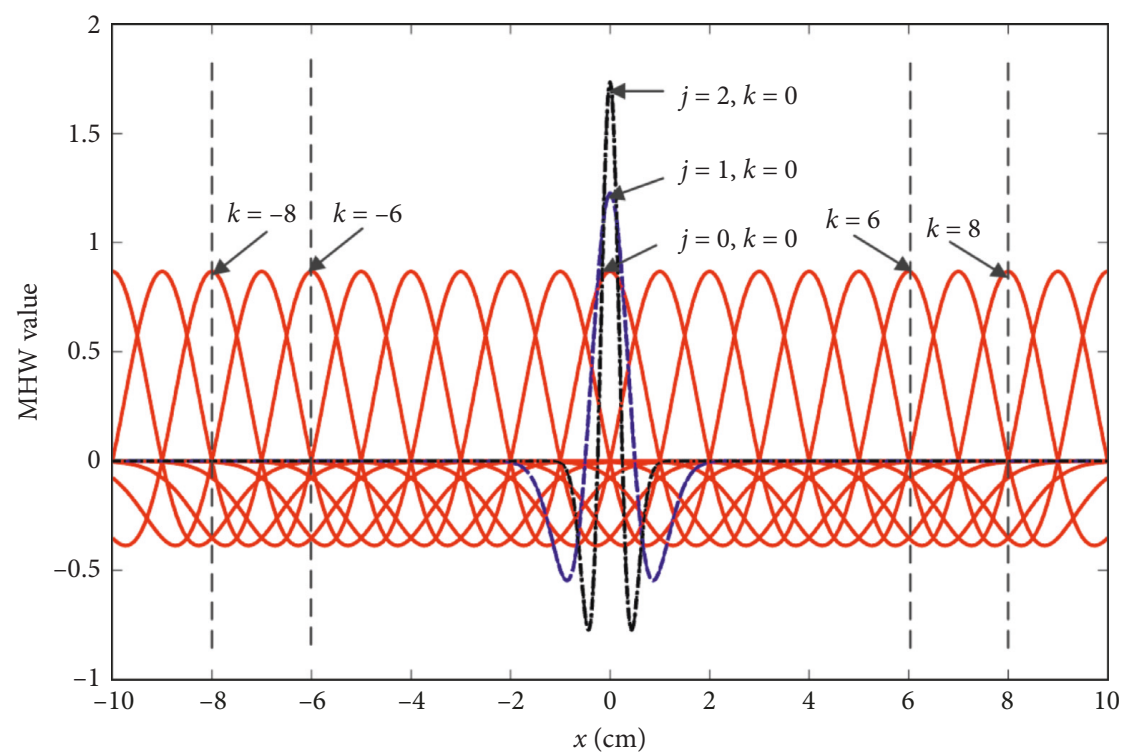

Figure 2: MHW values under different scaling and translation parameters.

where $l(x)$ presents the greatest integer that is less than or equal to $x$ and $u(x)$ denotes the least integer that is greater than or equal to $x . m$ is the power exponent of the $\mathrm{ABH}$ region of the sandwich beam. For example, when the length domain of the sandwich beam is $(-6,6)$ and $m=2, j=0$, the value range of $k$ is $(-8,8)$. It can be known from equation (27) that the longer the length of the sandwich $\mathrm{ABH}$ beam, the larger the range of $k$, and the higher the power exponent of the $\mathrm{ABH}$ region, the larger the value of $j$. For any given sandwich $\mathrm{ABH}$ beam, the displacement field can be accurately fitted by adjusting the values of $j$ and $k$ to fulfill the calculation accuracy requirements.

\section{Numerical Simulation Results and Discussion}

3.1. FEM Validation of the Proposed Model. The geometric parameters and material parameters of the sandwich $\mathrm{ABH}$ beam are shown in Table 1. The boundary condition of the sandwich $\mathrm{ABH}$ beam is clamped free. There is a truncation at the end of the $\mathrm{ABH}$ region, with a thickness of $2 \mathrm{~mm}$. In order to verify the accuracy of the proposed semianalytical model of the sandwich $\mathrm{ABH}$ beam, the natural frequencies of the sandwich $\mathrm{ABH}$ beam is calculated, respectively, by the finite element method (FEM) and the semianalytical model. The model used in FEM validation is shown in Figure 3. In order to ensure the accuracy of the FEM calculation results, the mesh size of the $\mathrm{ABH}$ region is $1 \mathrm{~mm}$, while the mesh size of the remaining part is $4 \mathrm{~mm}$.

To verify the computational accuracy of the established model, the first 30 natural frequencies of the sandwich $\mathrm{ABH}$ beam under the clamped-free boundary condition without considering damping layers are calculated, as shown in Table 2. It can be seen that the first 30 natural frequencies obtained by the presented model and FEM are approximately equal with an error less than 2 percent. The modal shapes of the bare $\mathrm{ABH}$ beam calculated with the present
TABLE 1: Geometrical and material parameters of the sandwich $\mathrm{ABH}$ beam.

\begin{tabular}{lc}
\hline Geometrical parameters & Material parameters \\
\hline$\varepsilon=0.006$ & $\rho_{\mathrm{b} 1}=7800 \mathrm{~kg} / \mathrm{m}^{3}$, \\
& $\rho_{\mathrm{b} 2}=2700 \mathrm{~kg} / \mathrm{m}^{3}$, and \\
$\rho_{\mathrm{b} 3}=7800 \mathrm{~kg} / \mathrm{m}^{3}$ \\
$m=2$ & $E_{\mathrm{b} 1}=210 \mathrm{GPa}, E_{\mathrm{b} 2}=69 \mathrm{GPa}$, and \\
$h_{\mathrm{b} 1}=0.5 \mathrm{~cm}, h_{\mathrm{b} 2}=1 \mathrm{~cm}$, and & $E_{\mathrm{b} 1}=0.005, \eta_{\mathrm{b} 2}=0.005$, and \\
$h_{\mathrm{b} 3}=0.5 \mathrm{~cm}$ & $\eta_{\mathrm{b} 3}=0.005$ \\
$x_{0}=5 \mathrm{~cm}$ & $\rho_{\mathrm{d}}=1200 \mathrm{~kg} / \mathrm{m}^{3}$ \\
$x_{\mathrm{d} 1}=6 \mathrm{~cm}$ and $x_{\mathrm{d} 2}=8 \mathrm{~cm}$ & $E_{\mathrm{d}}=12 \mathrm{MPa}$ \\
$x_{\mathrm{b} 1}=7.58 \mathrm{~cm}, x_{\mathrm{b} 2}=8.87 \mathrm{~cm}$, & $\eta_{\mathrm{d}}=0.5$ \\
and $x_{\mathrm{b} 3}=45 \mathrm{~cm}$ & \\
$h_{\mathrm{d}}=0.2 \mathrm{~cm}$ and $h_{\mathrm{t}}=0.2 \mathrm{~cm}$ &
\end{tabular}

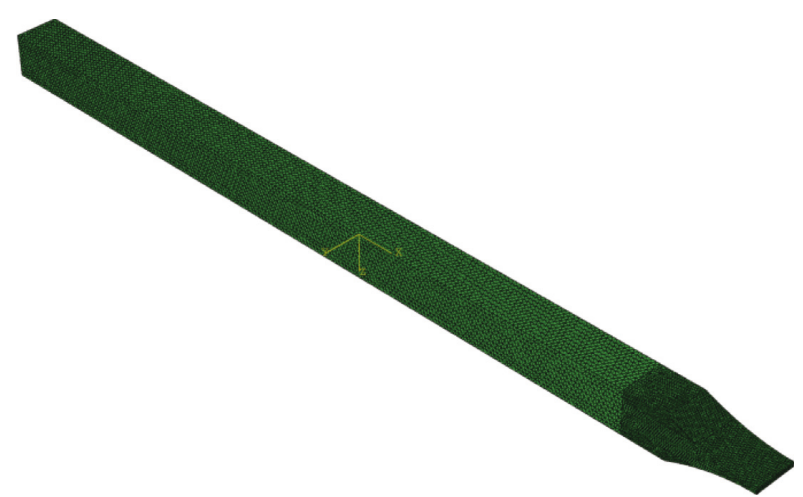

FIGURE 3: Model used in FEM validation.

model and FEM method are shown in Figure 4. In Figure 4, the starting point of the $x$-axis is the right end of the bare $\mathrm{ABH}$ beam and it can be seen that the modal shapes computed by the present model also agree well with those 
TABLE 2: Comparison of the first 30 natural frequencies obtained by the present model and FEM.

\begin{tabular}{lccc}
\hline $\begin{array}{l}\text { Natural } \\
\text { frequency }\end{array}$ & Present model & FEM & Error $(\%)$ \\
\hline$\omega_{1}$ & 121.65 & 121.74 & -0.070 \\
$\omega_{2}$ & 142.21 & 142.56 & -0.247 \\
$\omega_{3}$ & 751.74 & 748.92 & 0.376 \\
$\omega_{4}$ & 869.24 & 865.82 & 0.392 \\
$\omega_{5}$ & 1765.8 & 1767.2 & -0.078 \\
$\omega_{6}$ & 2050.4 & 2044.6 & 0.286 \\
$\omega_{7}$ & 2331.9 & 2321.5 & 0.447 \\
$\omega_{8}$ & 3493.5 & 3469.3 & 0.408 \\
$\omega_{9}$ & 3895.3 & 3875.3 & 0.515 \\
$\omega_{10}$ & 4298.9 & 4301.5 & -0.060 \\
$\ldots$ & $\ldots$ & $\ldots$ & $\ldots$ \\
$\omega_{21}$ & 13285 & 13216 & 0.521 \\
$\omega_{22}$ & 14816 & 14723 & 0.634 \\
$\omega_{23}$ & 16024 & 15922 & 0.640 \\
$\omega_{24}$ & 16016 & 15929 & 0.544 \\
$\omega_{25}$ & 17386 & 17295 & 0.528 \\
$\omega_{26}$ & 17936 & 17837 & 0.554 \\
$\omega_{27}$ & 19141 & 19019 & 0.639 \\
$\omega_{28}$ & 19131 & 19352 & -1.143 \\
$\omega_{29}$ & 21105 & 21023 & 0.390 \\
$\omega_{30}$ & 21224 & 21118 & 0.501 \\
\hline
\end{tabular}

calculated by the FEM method. It is proved that the presented model has good precision for solving the dynamic response of the sandwich $\mathrm{ABH}$ beam.

3.2. ABH Effect of the Sandwich Beam. According to the geometric and material parameters in Table 1, the acceleration responses of the $\mathrm{ABH}$ region (measuring point $x_{m}=8.87 \mathrm{~cm}$ ) and the uniform beam region (measuring point $x_{m}=10.87 \mathrm{~cm}$ ) of the sandwich $\mathrm{ABH}$ beam without damping layers are calculated. They are compared with the acceleration responses of the sandwich uniform beam at the same measuring points, which are shown in Figure 5. A harmonic driving force of $10 \mathrm{~N}$ is applied at $x_{\mathrm{f}}=25 \mathrm{~cm}$, and the reference acceleration is $1 \mathrm{~m} / \mathrm{s}^{2}$. It is shown that, for a sandwich $\mathrm{ABH}$ beam structure with a truncation and no damping layers, the acceleration peak values and corresponding frequencies of the $\mathrm{ABH}$ region are very similar to that of the sandwich uniform beam at low frequencies and the peak values are significantly greater than the sandwich uniform beam in $2 \mathrm{kHz}$ to $8 \mathrm{kHz}$. It should be noted that when the location of the driving point is different, the vibration response of the structure also changes which is manly caused by the modal participation coefficient changing of some modes [25]. So there are only six peaks below $10 \mathrm{kHz}$ in the calculation when the driving point is located at $x_{\mathrm{f}}=25 \mathrm{~cm}$. The above phenomenon in the $\mathrm{ABH}$ region indicates that there is significant energy concentration in this area, which makes the vibration acceleration of the $\mathrm{ABH}$ region markedly increased. Meanwhile, as the calculation frequency increases from 0 to $10 \mathrm{kHz}$, the gap between two corresponding frequencies of the bare $\mathrm{ABH}$ beam and the uniform beam peaks also increases. For the uniform beam region of the sandwich $\mathrm{ABH}$ beam, the peak values of the acceleration are attenuated at middle frequency and high frequency, but it still increases at about $2 \mathrm{kHz}$.

To further investigate the $\mathrm{ABH}$ effect, the flexural wave focalization effect of the bare $\mathrm{ABH}$ beam is studied in the time domain with the commercial software COMSOL Multiphysics. The position and amplitude of the driving force is the same as above, and the frequency of the driving force is $100 \mathrm{kHz}$. The displacement of the bare ABH beam along the $z$-axis is shown in Figure 6. In Figure 6, the direction of the view is a top view and the $\mathrm{ABH}$ regions are located at the right end of the beam. Figure 6(a) is the displacement of the bare $\mathrm{ABH}$ beam when the action time is $1.1 e-4 \mathrm{~s}$, and at this time, we can see that the flexural wave is propagating from the position of the excitation point to both ends of the ABH beam. Figure 6(b) is the displacement of the bare $\mathrm{ABH}$ beam when the action time is $2.8 e-4 \mathrm{~s}$, and at this time, the flexural wave has been focalized in the $\mathrm{ABH}$ region. The wavelength of the flexural wave is compressed in this region, forming a high energy region in the acoustic black hole.

To conclude above analysis, for a sandwich-truncated $\mathrm{ABH}$ beam structure without damping layers, the $\mathrm{ABH}$ region produces a certain energy concentration effect in middle and high frequencies, but due to the existence of the truncation, the acceleration attenuation of the uniform beam region is not obvious and even get increased at some frequencies. In the actual manufacturing, it is impossible to achieve an $\mathrm{ABH}$ area without truncation. So that other measures should be taken to improve the vibration reduction effect of the sandwich $\mathrm{ABH}$ beam in application.

3.3. Effect of the Damping Layer. To evaluate the vibration reduction performance of the sandwich $\mathrm{ABH}$ beam, the influence of the damping layer parameters on the dynamic responses of the $\mathrm{ABH}$ region and uniform region of the sandwich $\mathrm{ABH}$ beam will be analyzed. The damping layers coupled with the sandwich $\mathrm{ABH}$ beam have a thickness of $2 \mathrm{~mm}$ and a length of $20 \mathrm{~cm}$ (along the $x$-axis direction) with a damping loss factor of 0.5 . The magnitude and position of the harmonic force and measuring points keep unchanged. It is observed from Figure 7 that even if the thickness of the damping layers is only $2 \mathrm{~mm}$, they can still have a very significant vibration reduction effect on the sandwich $\mathrm{ABH}$ beam, especially in the middle and high frequencies. For the $\mathrm{ABH}$ region, the attenuation of the acceleration peak values at about $9 \mathrm{kHz}$ reaches $18.8 \mathrm{~dB}$ and, in $2 \mathrm{kHz}-4 \mathrm{kHz}$ domain, it also reaches more than $7 \mathrm{~dB}$. Besides, for the uniform beam region, the attenuation is $12.5 \mathrm{~dB}$ at about $4 \mathrm{kHz}$ and it reaches more than $7 \mathrm{~dB}$ in other corresponding frequencies.

To summarize, in order to achieve an obvious vibration reduction effect, it is important to attach damping layers on the $\mathrm{ABH}$ region of the sandwich $\mathrm{ABH}$ beam with truncation even if the length and thickness of the damping layer are much smaller than the sandwich ABH beam.

Figure 8 shows the effect of the damping loss factor of the damping layer on the vibrational acceleration of the $\mathrm{ABH}$ region and the uniform beam region. As observed in Figure 8 , the larger the damping loss factor of the damping 

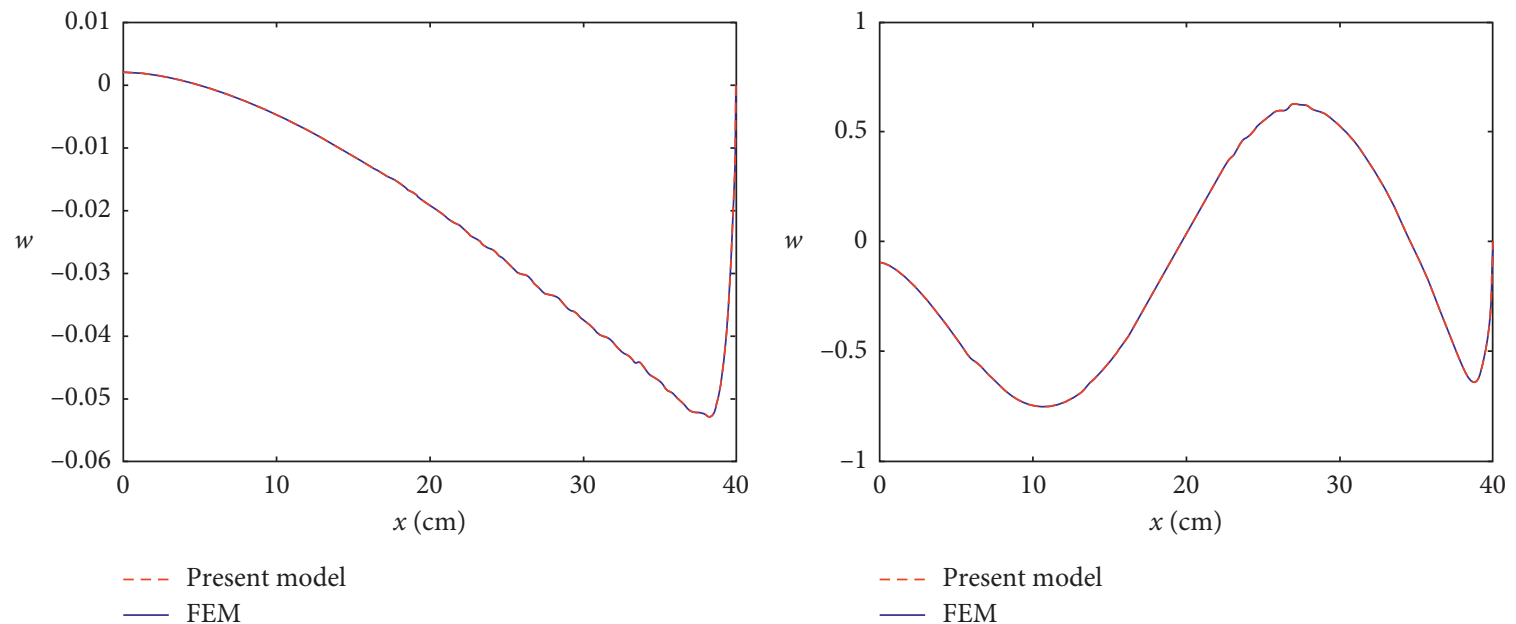

(a)

(b)
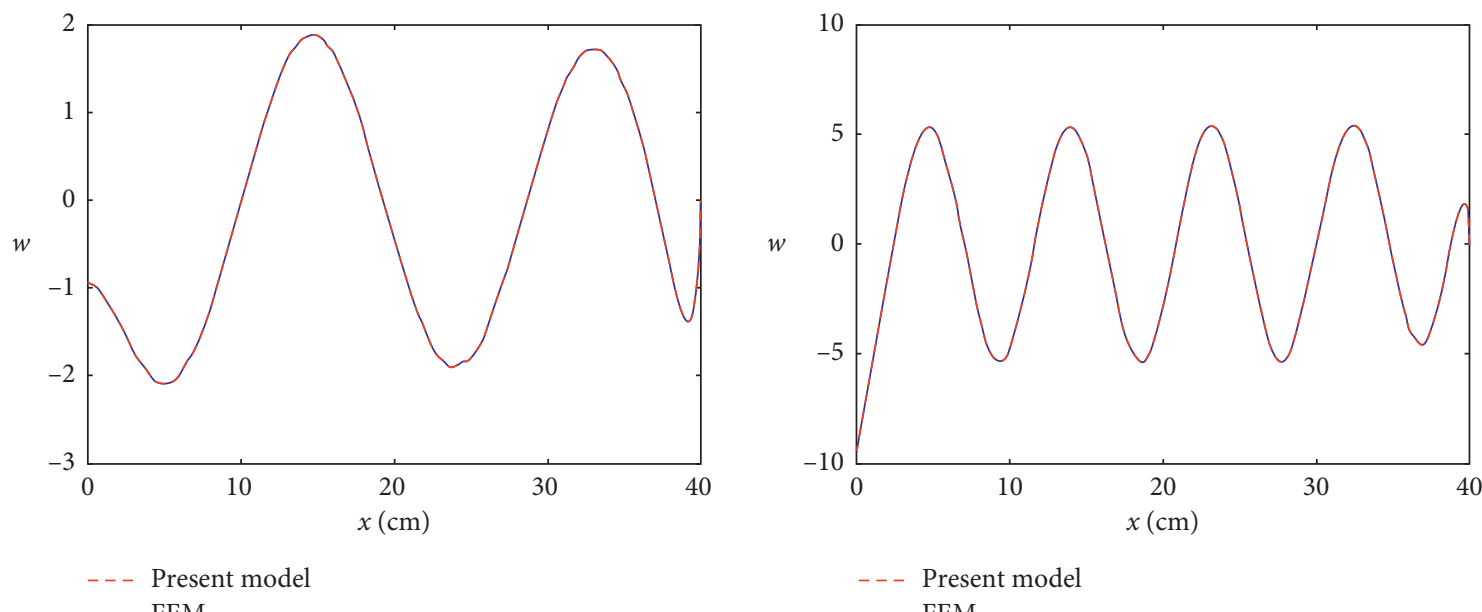

(c)

(d)

FIGURE 4: Modal shapes of the bare ABH beam calculated with the present model and FEM method: (a) first mode; (b) sixth mode; (c) twelfth mode; (d) twenty-ninth mode.

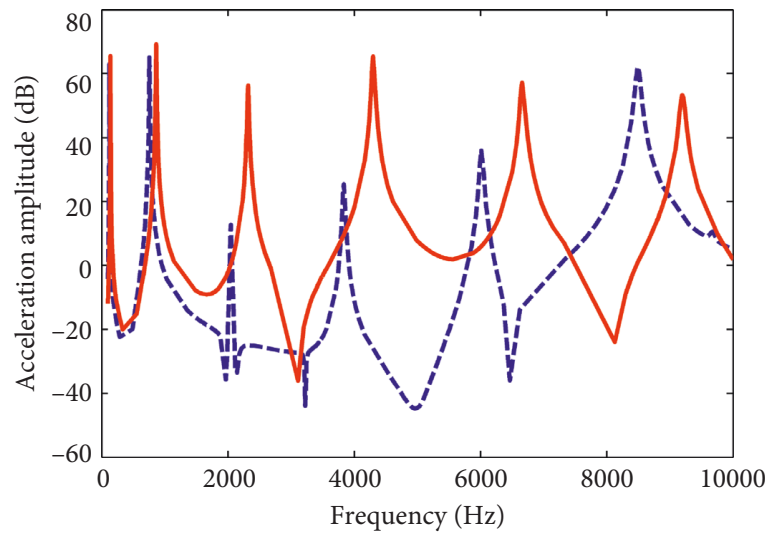

- - - Uniform beam

_ Bare ABH beam

(a)

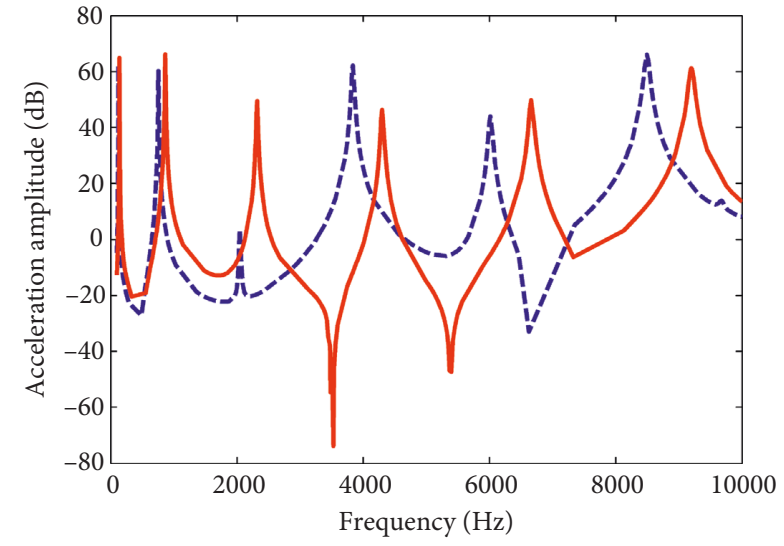

- - - Uniform beam

— Bare ABH beam

FiguRE 5: Acceleration responses of the bare ABH beam and the uniform beam: (a) ABH region $\left(x_{m}=8.87 \mathrm{~cm}\right.$ ); (b) uniform beam region $\left(x_{m}=10.87 \mathrm{~cm}\right)$. 


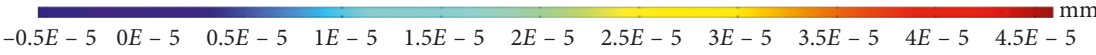

(a)

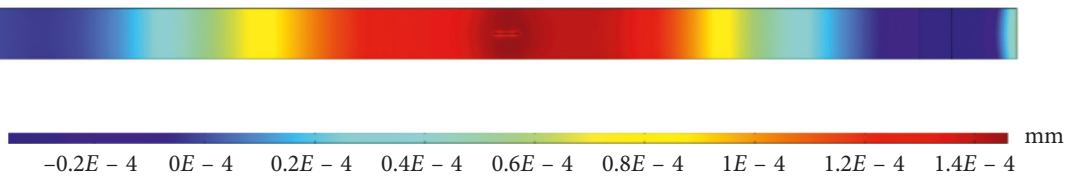

(b)

Figure 6: Displacement of bare ABH beam at different times: (a) $t=1.1 e-4 \mathrm{~s}$; (b) $t=2.8 e-4 \mathrm{~s}$.

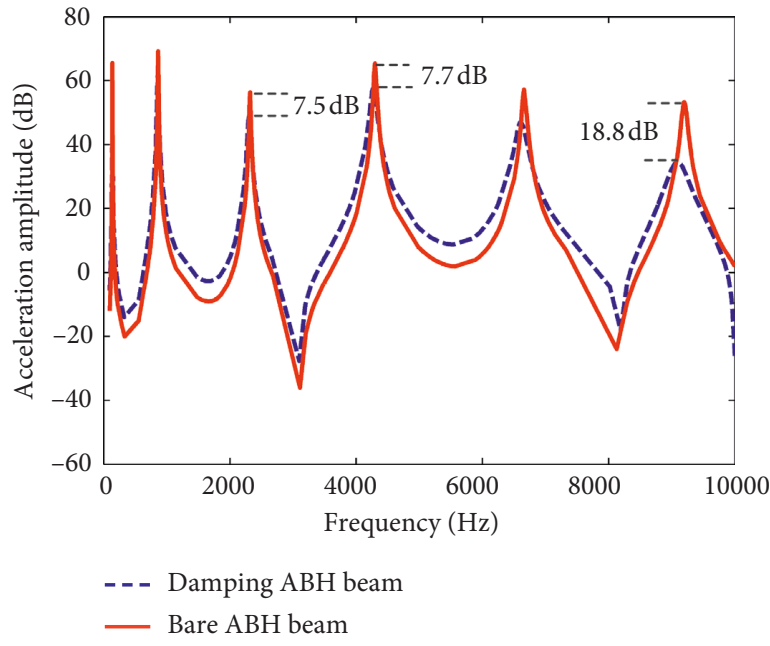

(a)

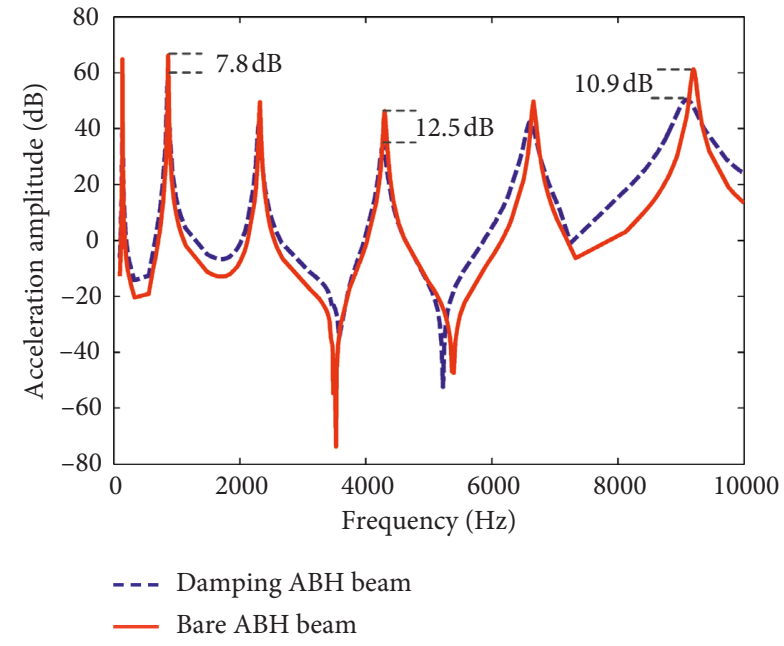

(b)

Figure 7: Effects of the damping layers on the acceleration responses: (a) ABH region $\left(x_{m}=8.87 \mathrm{~cm}\right.$ ); (b) uniform beam region $\left(x_{m}=10.87 \mathrm{~cm}\right)$.

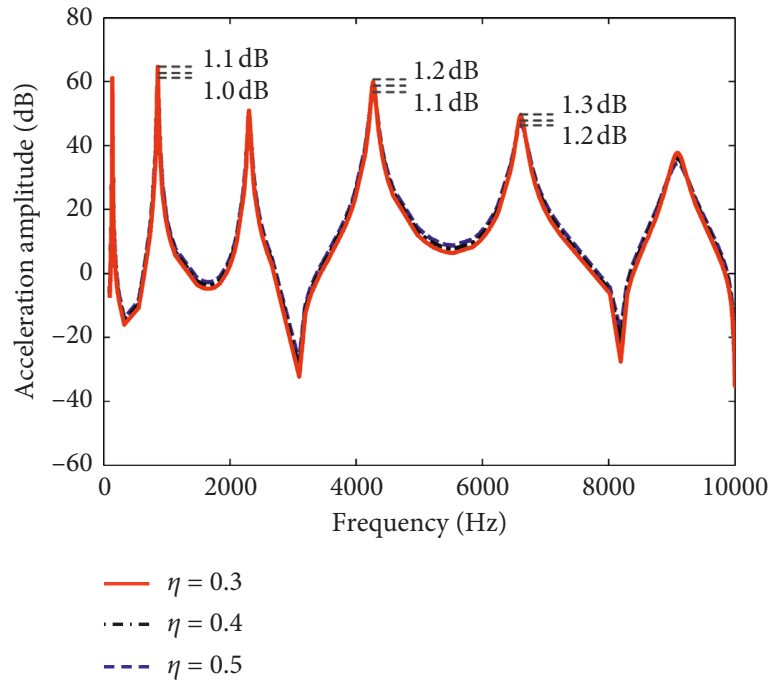

(a)

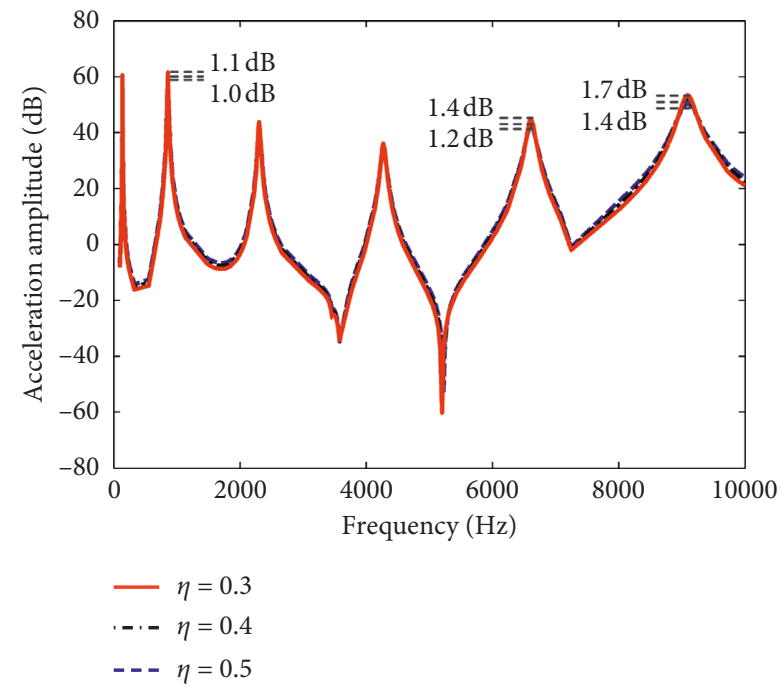

(b)

Figure 8: Effects of the damping loss factor of the damping layers on acceleration responses: (a) ABH region $\left(x_{m}=8.87 \mathrm{~cm}\right.$ ); (b) uniform beam region $\left(x_{m}=10.87 \mathrm{~cm}\right)$. 
layer, the greater the vibration acceleration attenuation of the sandwich $\mathrm{ABH}$ beam. In the $\mathrm{ABH}$ region, for every 0.1 increase in the damping loss factor of the damping layer, the vibration acceleration of the sandwich $\mathrm{ABH}$ beam can achieve about $1.2 \mathrm{~dB}$ attenuation, among which the maximum value is $1.3 \mathrm{~dB}$. Furthermore, the attenuation of the acceleration peak values corresponding to the high frequencies is slightly larger than the attenuation of the acceleration peak values corresponding to the low frequencies. For the uniform beam region, the attenuation trend of the vibration acceleration peak values corresponding to each frequency is similar to that of the $\mathrm{ABH}$ region as the damping loss factor of the damping layer increases. However, the influence of the damping loss factor variation on the uniform beam region is greater than that on the $\mathrm{ABH}$ region. The maximum peak values attenuation of the uniform beam region is $1.7 \mathrm{~dB}$ at about $9 \mathrm{kHz}$.

The influence of the thickness of the damping layer on the vibration acceleration response of the sandwich $\mathrm{ABH}$ beam structure is also studied. The results are shown in Figure 9, and it reveals that a significant vibration acceleration attenuation could be reached with every $1 \mathrm{~mm}$ increase in the thickness of the damping layer both for the $\mathrm{ABH}$ region and the uniform region of the sandwich $\mathrm{ABH}$ beam. The higher the corresponding frequencies, the greater the peak values attenuation. When the thickness of the damping layer reaches $3 \mathrm{~mm}$, the acceleration attenuations generated of the $\mathrm{ABH}$ region and the uniform beam region are $30.1 \mathrm{~dB}$ and $21.4 \mathrm{~dB}$ at about $9 \mathrm{kHz}$ compared with the thickness of the damping layer being $2 \mathrm{~mm}$. With this parameter, it has the effect of completely suppressing the peaks of acceleration response at this corresponding frequency.

The mode shapes of $\mathrm{ABH}$ beams with different damping layer thickness at around $9 \mathrm{kHz}$ are presented in Figure 10. It can be observed from Figure 10 that, for the three $\mathrm{ABH}$ beams with different damping layer thicknesses varying from $1 \mathrm{~mm}$ to $3 \mathrm{~mm}$, the mode shape of each $\mathrm{ABH}$ beam exists at $9150 \mathrm{~Hz}$. The modal loss factor is also computed to reveal the mechanism of vibration peak attenuation which is as shown in Figure 11. In Figure 11, we can see that the modal loss factor gets increased with the increasing of the damping layer thickness in a certain frequency domain and it can be concluded that the mechanism of the peaks attenuation in Figure 9 is the increase of the modal loss factor of the system. At $9150 \mathrm{~Hz}$, the damping loss factors of the three damping $\mathrm{ABH}$ beams with damping layer thickness varying from $1 \mathrm{~mm}$ to $3 \mathrm{~mm}$ are $6.78 e-4,2.99 e-2$, and $3.87 e-1$, respectively, and the huge difference in modal loss factors at $9150 \mathrm{~Hz}$ is the reason of the disappearance of the peak of the damping $\mathrm{ABH}$ beam with damping layer of $3 \mathrm{~mm}$ thickness which is shown in Figure 9.

To summarize, it can be seen that the influence of the thickness variation of the damping layers on the acceleration response of the sandwich $\mathrm{ABH}$ beam is much greater than the variation of the damping loss factor. Therefore, in the application of the sandwich ABH beam, the selection of a damping layer of appropriate thickness can significantly improve the vibration attenuation effect of the entire system.

3.4. Effect of the Middle Layer. Unlike the traditional singlelayer $\mathrm{ABH}$ beam structures, the sandwich $\mathrm{ABH}$ beam with aluminum in the middle layer and steel in the upper and lower layers is studied in this paper. The effect of aluminum or steel as the middle layer material on vibration acceleration response of the sandwich $\mathrm{ABH}$ beam is shown in Figure 12. It is observed that the effect of the middle layer material on both the peak values and the corresponding frequencies is not obvious in the low-frequency domain. However, the frequencies corresponding to the peak values become larger as the material of the middle layer is replaced by aluminum from steel in middle- and high-frequency domains. For the $\mathrm{ABH}$ region, the peak value of vibration acceleration of the $\mathrm{ABH}$ beam with aluminum in the middle layer is $5.4 \mathrm{~dB}$ lower than that of steel in the middle layer when the frequency is around $9 \mathrm{kHz}$. However, it is $8.9 \mathrm{~dB}$ larger than that of steel in the middle layer when the frequency is at about $6 \mathrm{kHz}$. For the uniform beam region, the peak value of vibration acceleration of the $\mathrm{ABH}$ beam with aluminum in the middle layer is $4.7 \mathrm{~dB}$ lower than that of steel in the middle layer when the frequency is around $9 \mathrm{kHz}$.

The influence of the thickness variation of the aluminum layer on the vibration acceleration of the sandwich $\mathrm{ABH}$ beam structure will be further investigated. The thickness of the middle aluminum layer is $4 \mathrm{~mm}, 6 \mathrm{~mm}$, and $8 \mathrm{~mm}$, respectively. The thickness of the steel layers changes with the thickness of the middle aluminum layer, so as to ensure that the total thickness of the sandwich $\mathrm{ABH}$ beam remains $20 \mathrm{~mm}$. Figure 13 shows the acceleration responses of the $\mathrm{ABH}$ region and the uniform beam region of the sandwich $\mathrm{ABH}$ beam structure when the thickness of the aluminum layer is changing from $4 \mathrm{~mm}$ to $8 \mathrm{~mm}$. As can be seen, the larger the thickness of the aluminum layer, the larger the frequencies corresponding to the peaks of the acceleration in middle- and high-frequency domains. At low frequency, the peak values and the frequencies corresponding to the peak values are not affected obviously by the thickness variation of the aluminum layer. But at the frequency of around $9 \mathrm{kHz}$, the larger the thickness of the aluminum layer, the smaller the peak values of both the $\mathrm{ABH}$ region and the uniform beam region.

\section{Experimental Validations}

An experiment system was conducted to validate the accuracy of the numerical simulation. The geometric parameters of the sandwich $\mathrm{ABH}$ beam are the same as in Table 1 . The non-ABH end of the sandwich beam is clamped on the fixture, and the length of the clamped part is $4 \mathrm{~cm}$ so that the entire beam achieves the clamped-free boundary condition. The force rod of the shaker (Modal shop K2007E01) is attracted to the action point of the sandwich $\mathrm{ABH}$ beam by a magnetic seat. The location of the harmonic driving force of $10 \mathrm{~N}$ is $x_{\mathrm{f}}=25 \mathrm{~cm}$, and acceleration sensors 


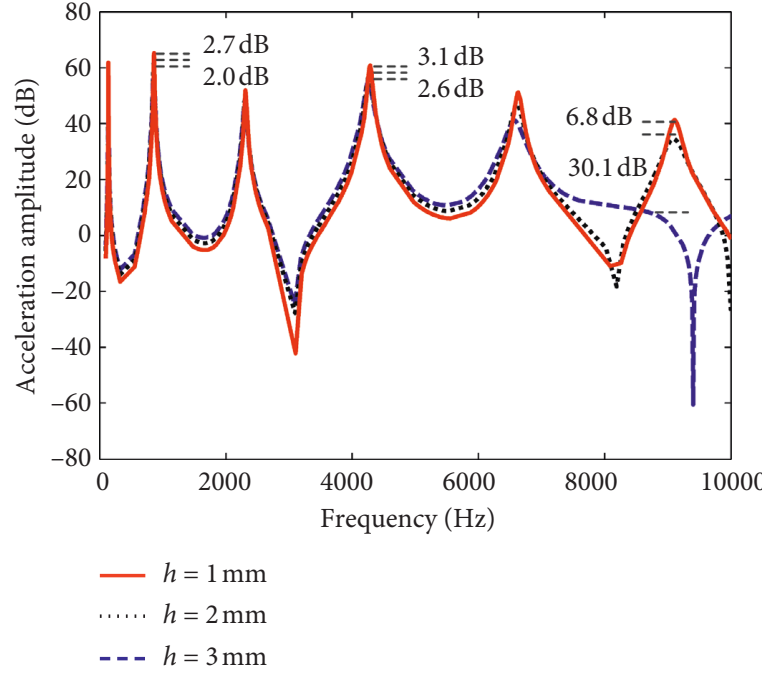

(a)

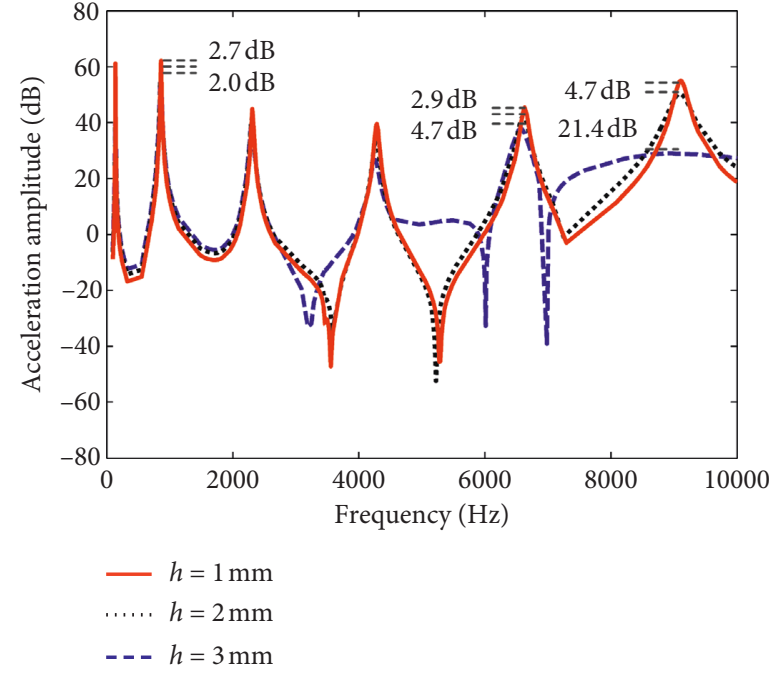

(b)

FiguRE 9: Effects of the damping layer thickness on acceleration responses: (a) $\mathrm{ABH}$ region $\left(x_{m}=8.87 \mathrm{~cm}\right.$ ); (b) uniform beam region $\left(x_{m}=10.87 \mathrm{~cm}\right)$.

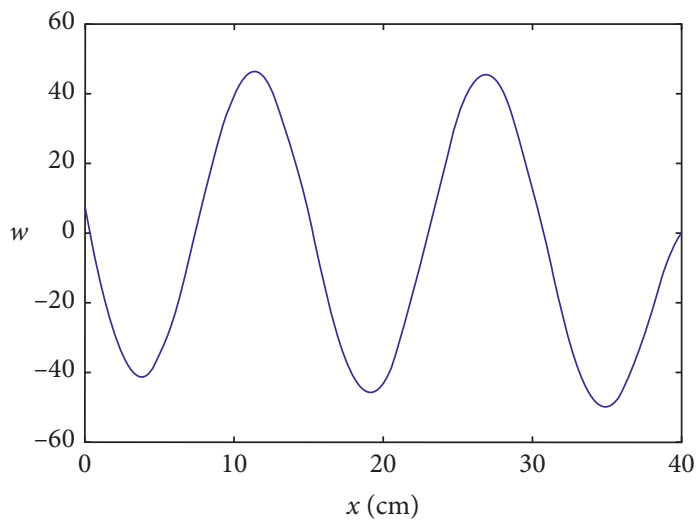

(a)

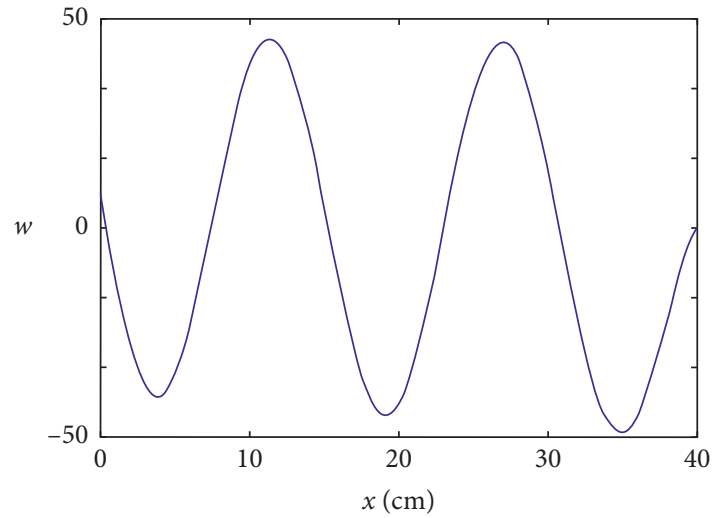

(b)

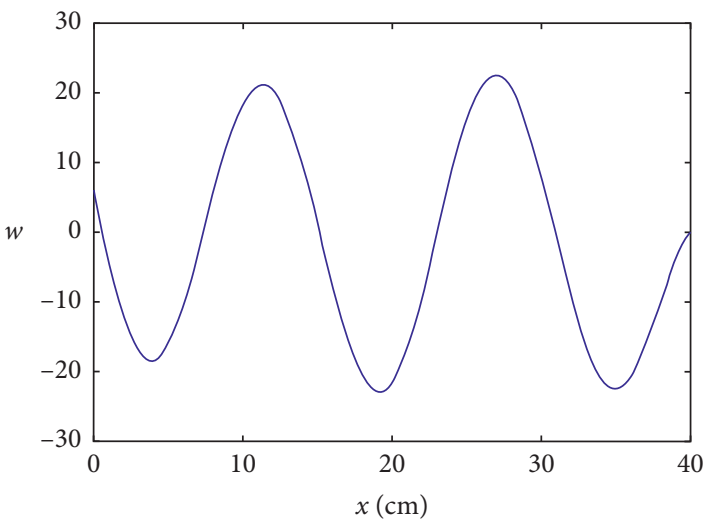

(c)

Figure 10: Mode shapes of ABH beams with different damping layer thickness at around $9 \mathrm{kHz}$ : (a) $h=1 \mathrm{~mm}$, frequency $=9141.59 \mathrm{~Hz}$; (b) $h=2 \mathrm{~mm}$, frequency $=9158.9 \mathrm{~Hz}$; (c) $h=3 \mathrm{~mm}$, frequency $=9158.22 \mathrm{~Hz}$.

are placed in the $\mathrm{ABH}$ region and the uniform beam region to measure the acceleration response. The $m+p$ data acquisition system (VibPlot-8) generates a sinusoidal signal from $20 \mathrm{~Hz}$ to $12000 \mathrm{~Hz}$ to feed the shaker and collects the signals of two acceleration sensors. Photograph and schematic diagram of the experimental system are shown in 


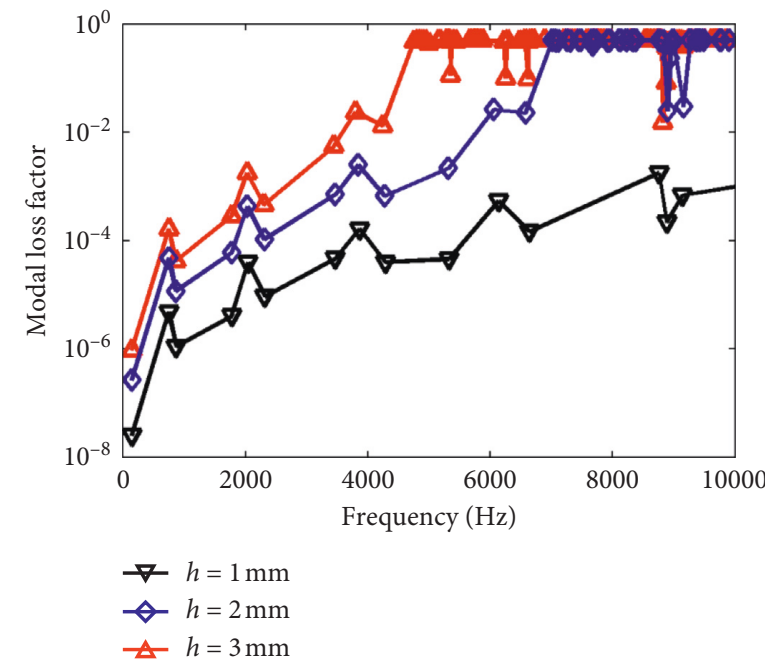

(a)

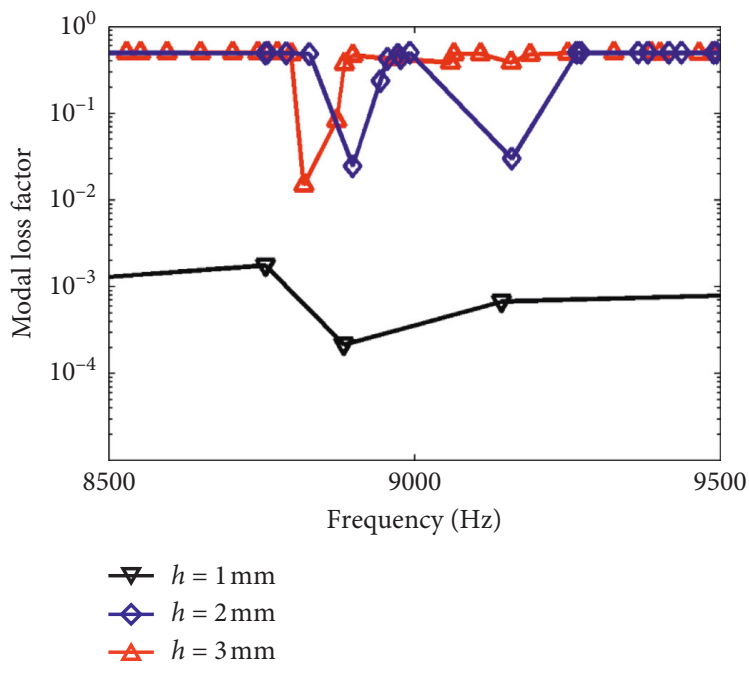

(b)

Figure 11: Modal loss factor of $\mathrm{ABH}$ beams with different damping layer thickness: (a) calculation frequency from 0 to $10 \mathrm{kHz}$; (b) calculation frequency from 8500 to $9500 \mathrm{~Hz}$.

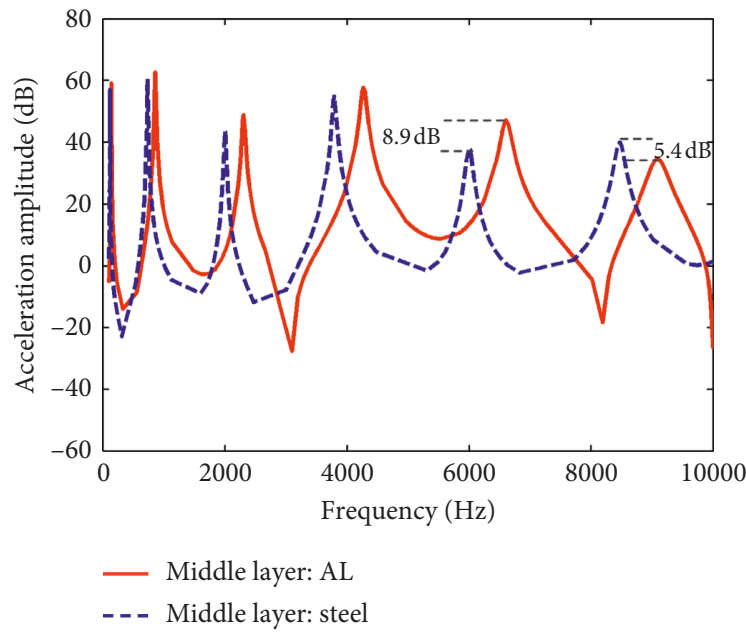

(a)

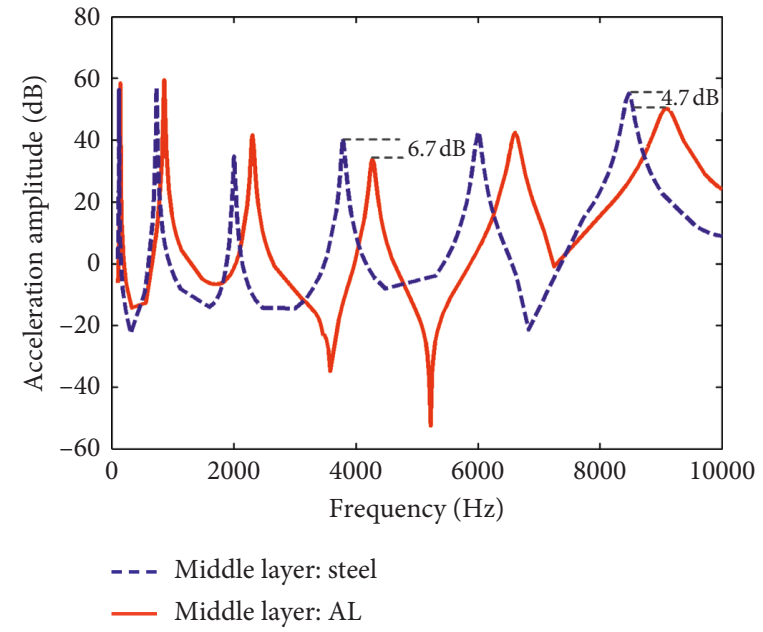

(b)

Figure 12: Effects of the middle layer material on acceleration responses: (a) ABH region $\left(x_{m}=8.87 \mathrm{~cm}\right.$ ); (b) uniform beam region $\left(x_{m}=10.87 \mathrm{~cm}\right)$.

Figure 14. The sandwich $\mathrm{ABH}$ beam structure was manufactured, with the middle layer material being aluminum and the upper and lower layers being steel. The aluminum material is $2 \mathrm{~A} 12$ aluminum alloy, and the steel material is 45 steel. The three layers of the sandwich $\mathrm{ABH}$ beam are bonded by thin metal glue.

The acceleration response of the $\mathrm{ABH}$ region of the sandwich $\mathrm{ABH}$ beam structure was measured and compared with the numerical simulation results, as shown in Figure 15. It can be seen from Figure 15 that the numerical simulation results in 0 to $8 \mathrm{kHz}$ domain agree well with the experimental results, in terms of both the acceleration peak values and corresponding frequencies. At $9 \mathrm{kHz}$, an increasing error compared with the measured peak values and corresponding frequency of the acceleration is mainly because the shear and torsional effects are ignored in the Euler-Bernoulli beam theory, resulting in an error in calculation of the vibration of the sandwich $\mathrm{ABH}$ beam in the high-frequency domain.

\section{Conclusions}

In this paper, a sandwich acoustic black hole beam has been proposed and a semianalytical model of the sandwich $\mathrm{ABH}$ beam with truncation has been established. The displacement field of the proposed $\mathrm{ABH}$ beam is fitted by the Mexican wavelet function, and the accuracy of the model of the sandwich $\mathrm{ABH}$ beam has been verified by the FEM method.

We have investigated the vibrational acceleration responses of the $\mathrm{ABH}$ region and the uniform region of the 


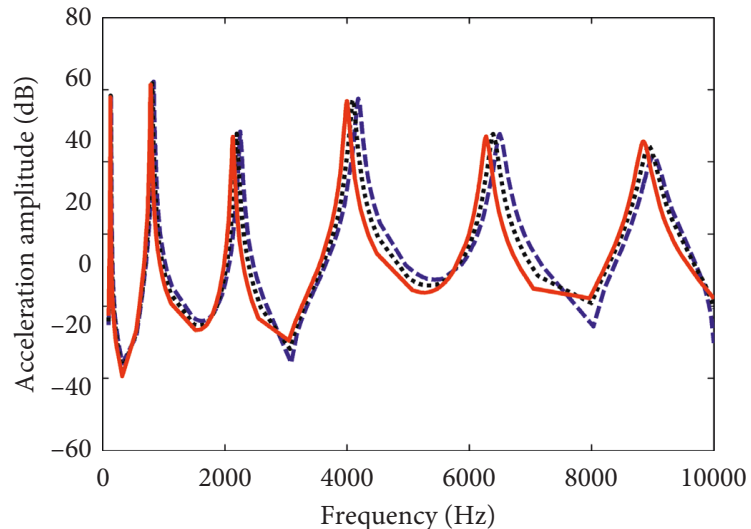

- AL layer: $4 \mathrm{~mm}$

...... AL layer: $6 \mathrm{~mm}$

--- AL layer: $8 \mathrm{~mm}$

(a)

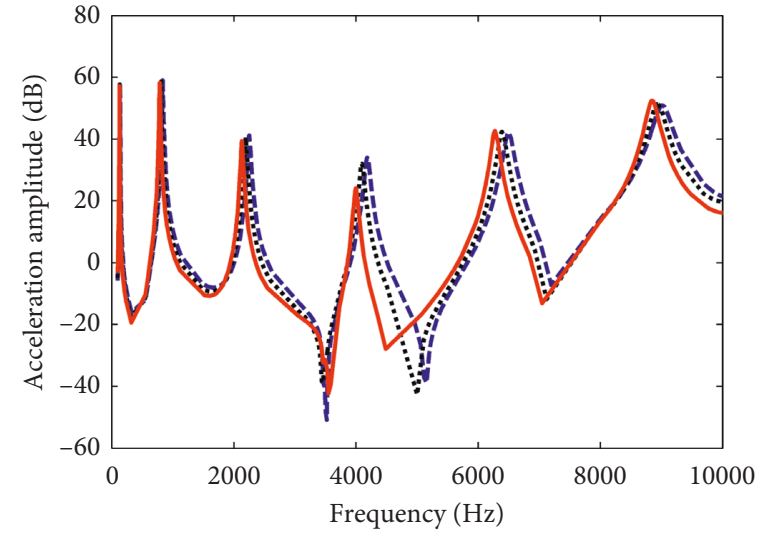

- AL layer: $4 \mathrm{~mm}$

…. AL layer: $6 \mathrm{~mm}$

- - - AL layer: $8 \mathrm{~mm}$

(b)

FIGURE 13: Effect of the aluminum layer thickness on acceleration responses: (a) ABH region $\left(x_{m}=8.87 \mathrm{~cm}\right)$; (b) uniform beam region $\left(x_{m}=10.87 \mathrm{~cm}\right)$.

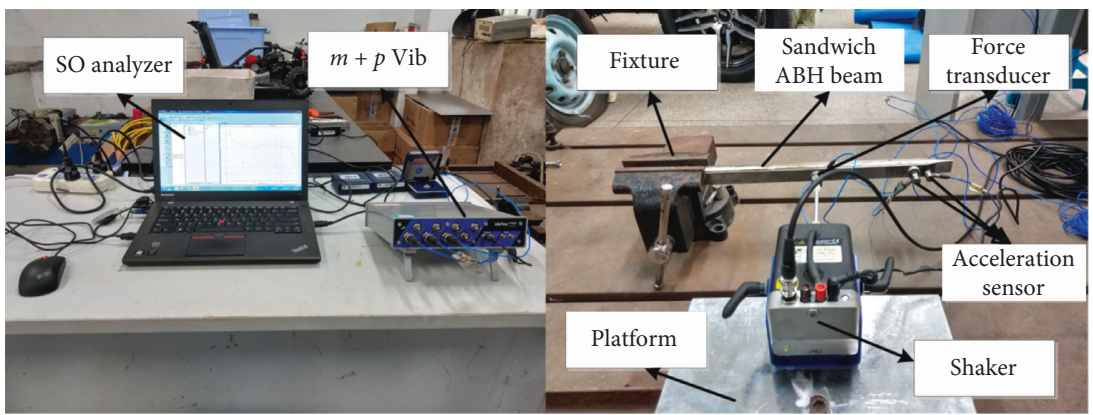

(a)

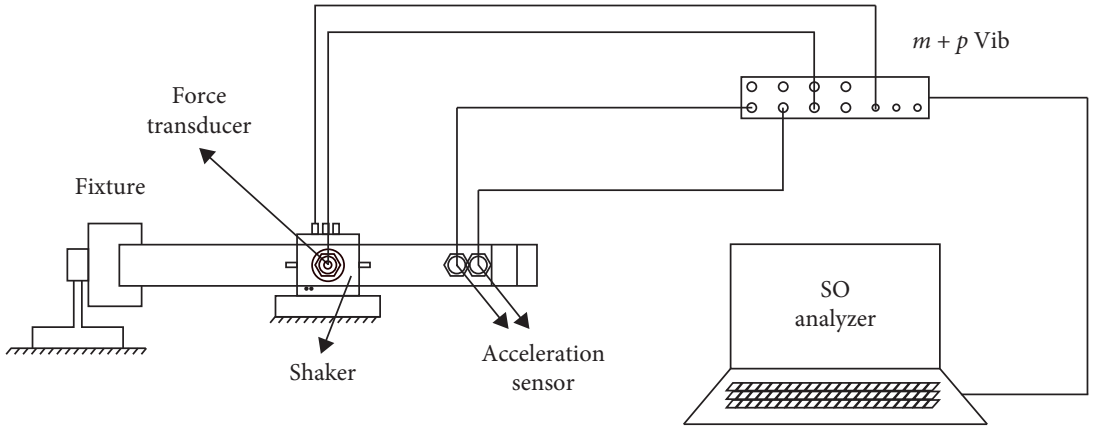

(b)

FIGURE 14: Experimental set-up: (a) photograph of the experiment system; (b) schematic of the experiment system.

sandwich $\mathrm{ABH}$ beam with the middle layer being aluminum and the upper and lower layers being steel. Simulations reveal that, for the bare $\mathrm{ABH}$ beam, there is a certain energy concentration effect in the $\mathrm{ABH}$ region in middle and high frequencies. The damping layers attached on the sandwich $\mathrm{ABH}$ beam can significantly improve the vibration suppression effect of both the $\mathrm{ABH}$ region and the uniform beam region. In the high-frequency domain of $9 \mathrm{kHz}$, the
$\mathrm{ABH}$ region and the uniform beam region have attenuation effects of $18.8 \mathrm{~dB}$ and $10.9 \mathrm{~dB}$ when the damping layers are applied, and the attenuation effect being more than $7 \mathrm{~dB}$ in middle- and low-frequency domains. It has been shown that, for every 0.1 increase in the damping loss factor of the damping layers, the acceleration peak values of the $\mathrm{ABH}$ region and the uniform beam region can be attenuated by about $1 \mathrm{~dB}$. Numerical results also indicate that the influence 


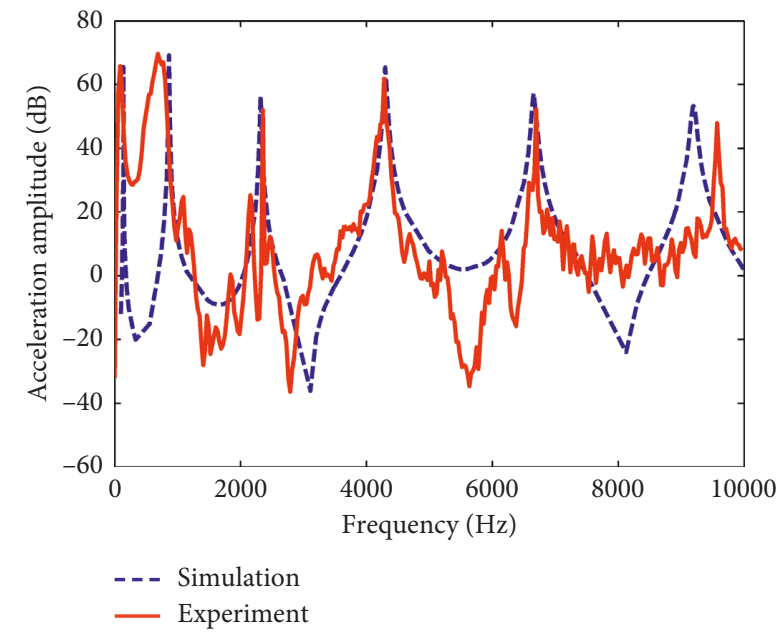

FIGURE 15: Comparison between the numerical simulation and the experimental results.

of the damping layer thickness on the dynamic response of the sandwich $\mathrm{ABH}$ beam is very significant. When the thickness of the damping layer is increased to $3 \mathrm{~mm}$, the high-frequency acceleration peaks at $9 \mathrm{kHz}$ can be completely suppressed. It has been concluded that the material and thickness of the middle layer of the sandwich $\mathrm{ABH}$ beam can bring a vibration attenuation at around $9 \mathrm{KHz}$ both for the $\mathrm{ABH}$ region and the uniform beam region in the present model.

\section{Data Availability}

The data used to support the findings of this study are available from the corresponding author upon request.

\section{Conflicts of Interest}

The authors declare that there are no conflicts of interest regarding the publication of this paper.

\section{Acknowledgments}

This study was supported by the Science and Technology Support Program of Jiangsu, China (no. BE2014133), the Prospective Joint Research Program of Jiangsu, China (no. BY2014127-01), and the Achievement Transformation Project of Nanjing, China (no. 201701213). The financial support is gratefully acknowledged.

\section{References}

[1] L. Zhao, "Low-frequency vibration reduction using a sandwich plate with periodically embedded acoustic black holes," Journal of Sound and Vibration, vol. 441, pp. 165-171, 2019.

[2] X. Li and Q. Ding, "Sound radiation of a beam with a wedgeshaped edge embedding acoustic black hole feature," Journal of Sound and Vibration, vol. 439, pp. 287-299, 2019.

[3] V. V. Krylov and E. P. Bowyer, "Acoustic black holes: a new approach to vibration damping in light-weight structures," Proceedings of the Institute of Acoustics, vol. 35, no. 1, pp. 184-191, 2013.
[4] M. A. Mironov, "Propagation of a flexural wave in a plate whose thickness decreases smoothly to zero in a finite interval," Soviet Physics Acoustics-USSR, vol. 34, no. 3, pp. 318-319, 1988.

[5] J. Y. Lee and W. Jeon, "Vibration damping using a spiral acoustic black hole," Journal of the Acoustical Society of America, vol. 141, no. 3, pp. 1437-1445, 2017.

[6] E. P. Bowyer and V. V. Krylov, "Experimental study of sound radiation by plates containing circular indentations of powerlaw profile," Applied Acoustics, vol. 88, pp. 30-37, 2015.

[7] S. Foucaud, G. Michon, Y. Gourinat, A. Pelat, and F. Gautier, "Immersed acoustic black hole as a travelling wave absorber: understanding artificial cochlear mechanics," Acoustics, 2012.

[8] L. Zhao, S. C. Conlon, and F. Semperlotti, "Broadband energy harvesting using acoustic black hole structural tailoring," Smart Materials and Structures, vol. 23, no. 6, article 065021, 2014.

[9] L. Zhao, S. C. Conlon, and F. Semperlotti, “An experimental study of vibration based energy harvesting in dynamically tailored structures with embedded acoustic black holes," Smart Materials and Structures, vol. 24, no. 6, article 065039, 2015.

[10] V. V. Krylov, "New type of vibration dampers utilising the effect of acoustic 'black holes'," Acta Acustica United with Acustica, vol. 90, no. 5, pp. 830-837, 2004.

[11] V. V. Krylov and F. J. B. S. Tilman, "Acoustic 'black holes' for flexural waves as effective vibration dampers," Journal of Sound and Vibration, vol. 274, no. 3-5, pp. 605-619, 2004.

[12] E. Bowyer, D. O’Boy, and V. Krylov, "Damping of flexural vibrations in composite plates and panels containing one-and two-dimensional acoustic black holes," Acoustics, 2012.

[13] V. V. Krylov, "Geometrical-acoustics approach to the description of localized vibrational modes of an elastic solid wedge," Soviet Physics Technical Physics, vol. 35, no. 2, pp. 137-140, 1990.

[14] V. B. Georgiev, J. Cuenca, F. Gautier, L. Simon, and V. V. Krylov, "Damping of structural vibrations in beams and elliptical plates using the acoustic black hole effect," Journal of Sound and Vibration, vol. 330, no. 11, pp. 2497-2508, 2011.

[15] L. Tang, L. Cheng, H. Ji, and J. Qiu, "Characterization of acoustic black hole effect using a one-dimensional fullycoupled and wavelet-decomposed semi-analytical model," Journal of Sound and Vibration, vol. 374, pp. 172-184, 2016.

[16] J. Deng, L. Zheng, P. Zeng, Y. Zuo, and O. Guasch, "Passive constrained viscoelastic layers to improve the efficiency of truncated acoustic black holes in beams," Mechanical Systems and Signal Processing, vol. 118, pp. 461-476, 2019.

[17] Y. Wang, J. Du, and L. Cheng, "Power flow and structural intensity analyses of acoustic black hole beams," Mechanical Systems and Signal Processing, vol. 131, pp. 538-553, 2019.

[18] H. Ji, J. Luo, J. Qiu, and L. Cheng, "Investigations on flexural wave propagation and attenuation in a modified one-dimensional acoustic black hole using a laser excitation technique," Mechanical Systems and Signal Processing, vol. 104, pp. 19-35, 2018.

[19] M. Hajianmaleki and M. S. Qatu, "Vibrations of straight and curved composite beams: a review," Composite Structures, vol. 100, pp. 218-232, 2013.

[20] C. D. Bailey, "Direct analytical solutions to non-uniform beam problems," Journal of Sound and Vibration, vol. 56, no. 4, pp. 501-507, 1978.

[21] S. Abrate, "Vibration of non-uniform rods and beams," Journal of Sound and Vibration, vol. 185, no. 4, pp. 703-716, 1995. 
[22] H. Kobayashi and K. Sonoda, "Vibration and buckling of tapered rectangular plates with two opposite edges simply supported and the other two edges elastically restrained against rotation," Journal of Sound and Vibration, vol. 146, no. 2, pp. 323-337, 1991.

[23] S. F. Ng and Y. Araar, "Free vibration and buckling analysis of clamped rectangular plates of variable thickness by the Galerkin method," Journal of Sound and Vibration, vol. 135, no. 2, pp. 263-274, 1989.

[24] T. Hou and H. Qin, "Continuous and discrete Mexican hat wavelet transforms on manifolds," Graphical Models, vol. 74, no. 4, pp. 221-232, 2012.

[25] Z.-M. Zhao, M.-P. Sheng, and Y. Yang, "Vibration of a stiffened shell with a ribbed plate under multi-point excitations," Engineering Mechanics, vol. 11, p. 37, 2013. 


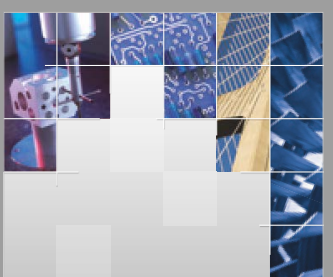

\section{Enfincering}
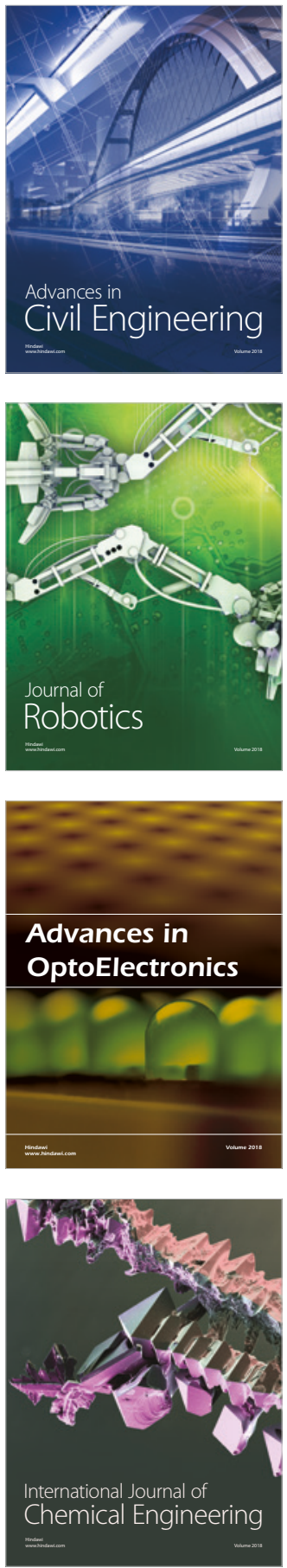

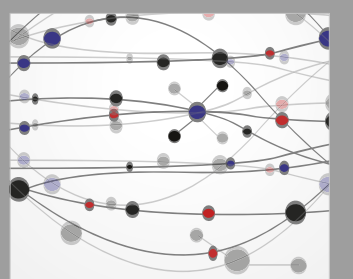

\section{Rotating \\ Machinery}

The Scientific World Journal

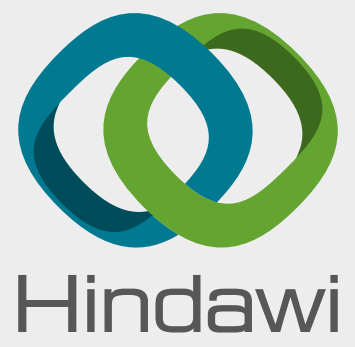

Submit your manuscripts at

www.hindawi.com
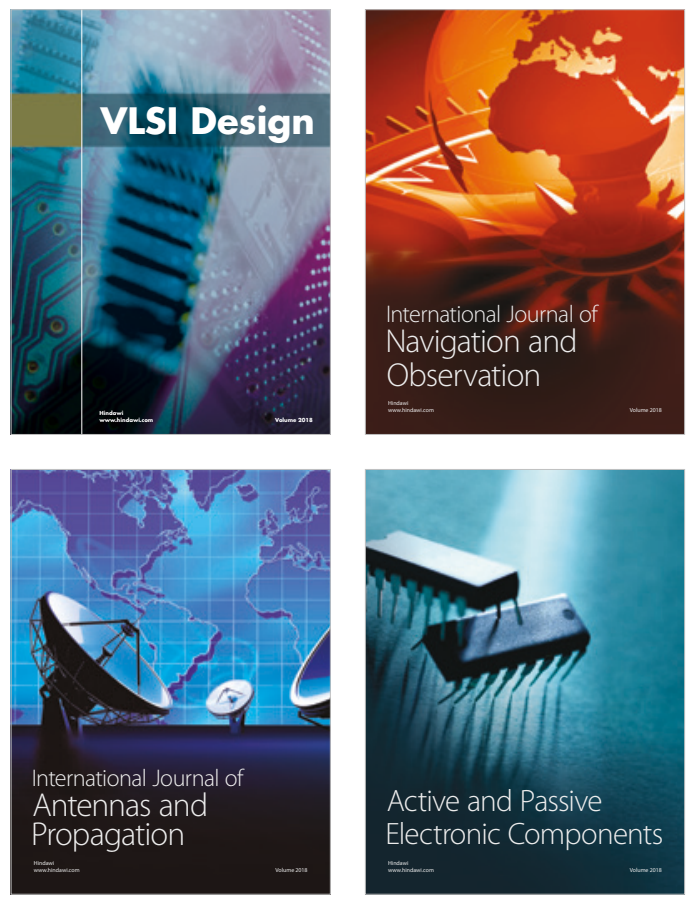
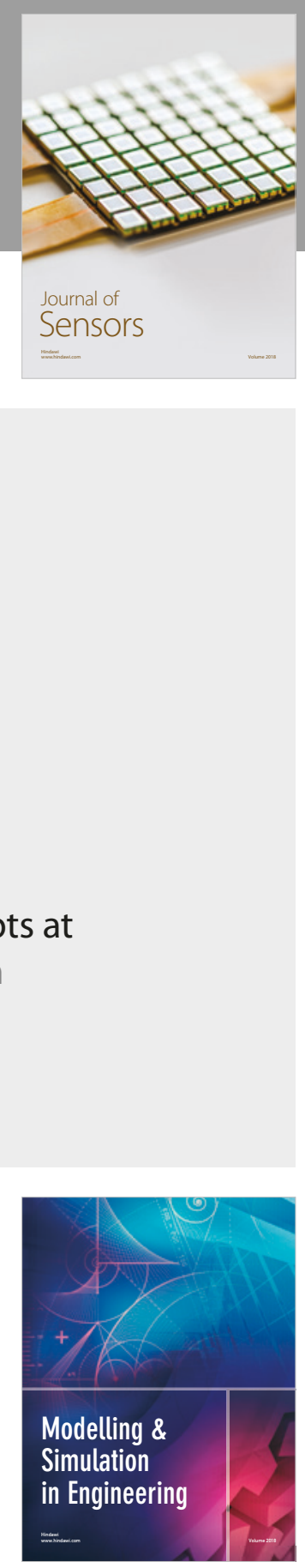

\section{Advances \\ Multimedia}
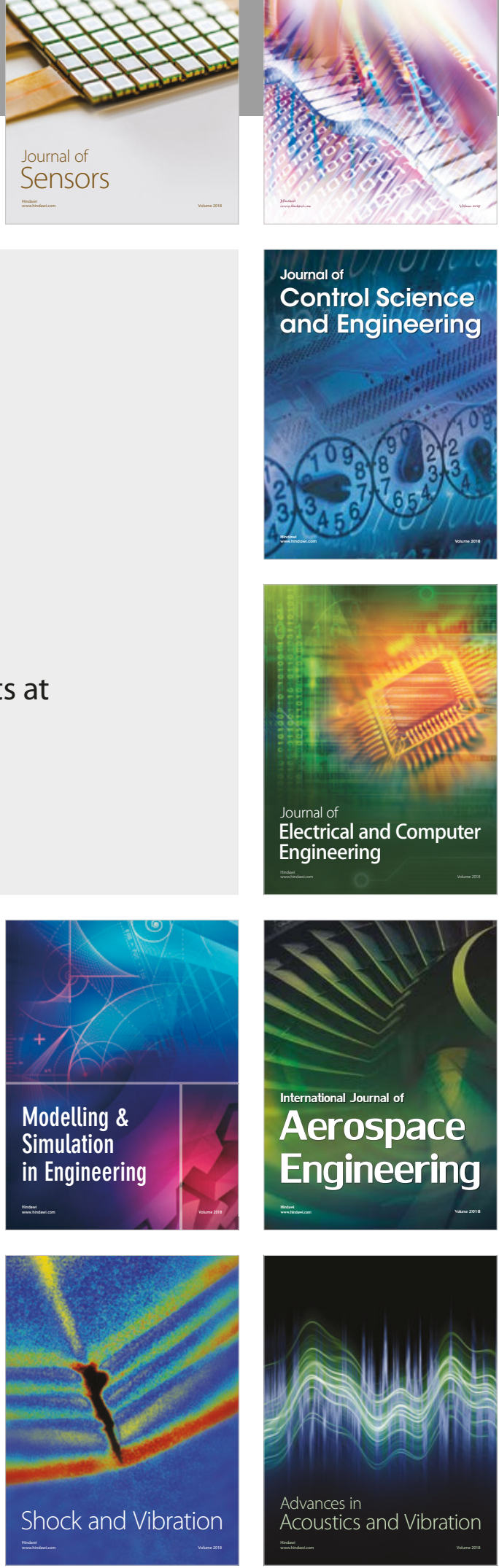